\title{
Trabalho e Políticas de Produção numa Fábrica de Caju em Moçambique
}

Fernando Bessa Ribeiro Universidade de Trás-os-

Montes e Alto Douro

\section{INTRODUÇÃO: LUGARES DE PRODUÇÃO E TRABALHO DE CAMPO}

Entre maio de 2001 e janeiro de 2004 efetuei dois períodos de trabalho campo em Moçambique para uma dissertação de doutoramento sobre as dinâmicas do capitalismo neste país (Ribeiro 2004). Em termos metodológicos o trabalho inscrevese nas "etnografias globais" (Burawoy et al. 2000), simultaneamente atentas às estruturas e processos de dimensão mundial e aos cotidianos de vida dos homens e das mulheres, nomeadamente nos espaços de produção. Considerando os impactos nos processos de mudança social provocados pela industrialização na África, esta etnografia procura seguir as propostas formuladas por Wolf (1982) e Wolf e Silverman (2001) em prol de uma antropologia mais histórica, capaz de dar conta das conexões, dependências e dinâmicas que se estabelecem entre as diferentes sociedades e culturas do sistema mundial. Perante a explosão da sociedade tradicional, como reconhece Geertz (1992), Wolf (1982: 390-391) lembra-nos que não podemos mais pensar nas sociedades como sistemas auto-sustentados e isolados, nem, tampouco, imaginar culturas como totalidades integradas orientadas para um todo autônomo e organizado. Por sua vez, a influência dos trabalhos relacionados com a antropologia da empresa e os estudos sobre os operários nas fábricas (v. Bazin 2001, Selim 2001, Burawoy 1979, Estanque 2000, Lazarus 2001, Flamant e Jeudy-Ballini 2002, Durão 2003, Granjo 2003 e 2004), é manifesta na etnografia realizada, sobretudo no que se relaciona com a identificação e compreensão das dimensões políticas da organização da produção e das relações sociais no interior das empresas.

Antes de se iniciar a pesquisa foi necessário negociar o acesso ao espaço de produção e escolher a estratégia metodológica. Refletindo sobre o trabalho de campo em empresas, Selim (2001: 69-71) refere justamente que a entrada do antropólogo em instituições desta natureza - propriedade privada, espaços rigorosamente delimitados e de acesso controlado - depende da vontade e da receptividade da administração. Mesmo quando se opta pela estratégia do antropólogo-disfarçado-de-operário, não se deixa de estar condicionado pelos constrangimentos impostos pela administração da 
empresa, o primeiro dos quais é o de franquear a porta do espaço de produção, quer dizer, conseguir ser admitido como trabalhador. Mas não só: como observou Portela (1986: 9), a posição no interior do grupo, isto é, o lugar que se vai ocupar no espaço da produção condiciona também aquilo que se observa e o relacionamento com os outros. Ao contrário do que fizeram, entre outros, Burawoy (1979) e Estanque (2000), optou-se por uma presença no espaço da produção que não implicou a prática continuada de uma tarefa produtiva. Ou seja, em lugar de se assumir a posição de operário num determinado setor, preferiu-se uma presença "não-produtiva", na esteira do que fizeram Granjo (2003 e 2004) para a produção de alumínio em Moçambique e para a indústria de refinação de petróleo em Portugal e Durão (2003) para as oficinas de tipografia em Portugal'. Assumindo de modo explícito a condição de investigador, esta presença não vinculada ao exercício de uma tarefa produtiva foi positiva para o processo de pesquisa, ao permitir a fácil circulação por todo o espaço de produção, observando as diversas fases produtivas e dialogando com os homens e as mulheres que nelas trabalhavam. Ainda que não se tenha exercido uma função laboral na estrutura organizacional, uma parte relevante da presença na fábrica foi ocupada com a aprendizagem rudimentar dos gestos técnicos necessários à execução das tarefas produtivas. Tal revelou-se de grande utilidade para a descrição etnográfica densa da cadeia produtiva e a compreensão do olhar e das representações dos operários acerca do seu trabalho, pois existem dimensões sensoriais e psicológicas às quais só se acedem com a experimentação concreta. Por outro lado, trabalhar lado-a-lado com os operários facilitou a minha inserção, acelerando a remoção das suas barreiras e desconfianças em relação aos propósitos da minha presença na fábrica.

\section{A EMPRESA E 0 BUROCRATA-BURGUÊS: A INSTALAÇÃO DE UMA FÁBRICA DE DESCASQUE DE CAJU}

A fábrica foi construída em 1997 com base num estudo de viabilidade econômica elaborado por um consultor com larga experiência no setor, antigo dirigente da Caju de Moçambique ${ }^{2}$. A escolha do lugar para instalar a fábrica recaiu em Jongué (distrito de Manjacaze), uma das áreas de maior produção de castanha de caju do sul de Moçambique. A estrutura principal, em forma de L, é um pavilhão com paredes formadas por blocos de cimento, ainda por rebocar, e cobertura em chapas de zinco e plástico (v. foto 1). É nela que se realizam todas as operações de processamento da castanha, com exceção da calibragem, efetuada num coberto junto ao átrio do edifício onde se alojam os dois

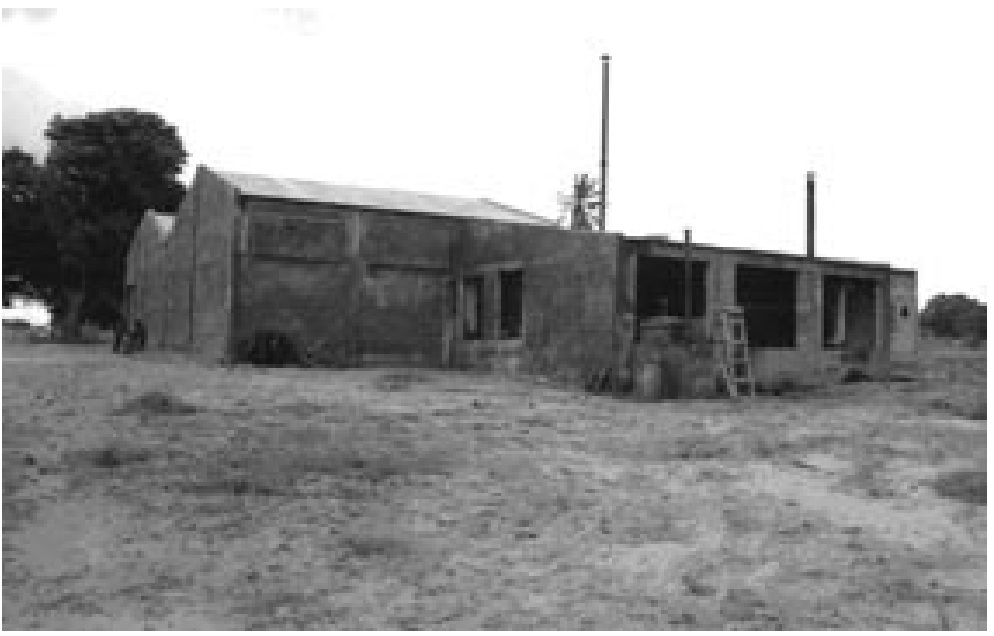

Foto 1. Vista geral do pavilhão principal da fábrica principais chefes da fábrica. 
Esta fábrica, cujo sistema produtivo conjuga mão-de-obra intensiva com artefatos mecânicos simples, é uma expressão concreta, como veremos mais à frente, das mudanças técnicas verificadas com a recomposição da indústria do caju nos anos 90. Como em muitas fábricas instaladas nesta década em Moçambique, o projeto seguiu de perto as propostas do Banco Mundial (BM), da Food and Agriculture Organization (FAO) e de outras instituições internacionais com trabalho feito na área do caju. A localização está de acordo com o prescrito: uma fábrica inserida na zona produtora, de modo a que a distância entre os produtores e as instalações de processamento fosse a mais curta possível. Para além dos custos de transporte serem insignificantes, a proximidade dos produtores de castanha de caju facilita a aquisição da matéria-prima. A nível técnico optou-se pelo Steam Heating Cutting System (SHCS), o chamado sistema indiano baseado no cozimento da castanha por vapor de água em associação com o corte da casca através de máquinas semi-mecânicas.

Esta pequena unidade industrial em meio rural revela-nos um dos modos de atuação da elite político-burocrática moçambicana na luta pela acumulação de propriedade e capital: a criação de uma empresa de raiz num setor considerado promissor pelos consultores a serviço do BM. Assim, a origem da fábrica é inseparável das opções políticas impostas pelas instituições do Consenso de Washington e adotadas pelo governo moçambicano, ou seja, das disposições que, no quadro das estruturas dominantes, condicionam as oportunidades e as escolhas dos atores sociais. Esta fábrica é um caso concreto da resposta empresarial encontrada pela elite local para manobrar em seu proveito as possibilidades oferecidas pelo novo quadro sócio-econômico produzido pelas políticas de "ajustamento estrutural". O responsável por este empreendimento é um membro da segunda geração da elite dirigente do país que paulatinamente tem ocupado lugares no aparelho de Estado e afastado a velha elite formada na luta armada. A sua carreira política e profissional é comum à dos jovens tecnocratas da Frelimo melhor sucedidos. Licenciado em economia, foi gestor numa empresa estatal, posteriormente governador de província. Em meados da década de 1990 passa a ministro da Agricultura. Conhecendo de perto os dossiês produzidos pelos consultores que apontavam como alternativa às grandes fábricas mecanizadas a pequena indústria baseada na utilização de mão-de-obra intensiva e sistemas técnicos simples, decidiu explorar em seu proveito as oportunidades proporcionadas pelo cargo exercido para montar a sua empresa. Mas a condição de ministro colocava-lhe alguns obstáculos políticos que entendeu contornar através de uma manobra jurídica hábil e relativamente freqüente: manter o controle da empresa sem estar formalmente comprometido com ela. Assim, caberia à esposa e aos filhos a responsabilidade jurídica na sociedade por quotas, constituída em setembro de 1996 e com sede em Maputo. Um burocrata empreendedor? Certamente que sim. Com formação acadêmica de nível superior, experiência feita na burocracia e nas empresas estatais, soube mobilizar os seus próprios recursos - algum capital e conhecimentos empresariais - e os do Estado, jogando com habilidade as "cartas" do poder político e as redes de clientela que gravitam em torno deste.

\section{A ORGANIZAÇÃO DO TRABALHO E O PROCESSO PRODUTIVO}

O processamento da castanha de caju é um trabalho colectivo que exige um cuidadoso planejamento e uma rigorosa coordenação dos operários em termos de tempo e sincronização das tarefas. O objectivo é obter 
a maior quantidade possível de amêndoa branca e inteira, as características mais valorizadas pelo mercado, através do recurso a equipamentos simples e trabalho humano utilizado de modo intensivo enquadrados por uma organização da produção que poderemos classificar de taylorismo atenuado. De fato, a cadeia operatória de tipo taylorista está presente, embora de modo imperfeito. Neste taylorismo atenuado temos uma divisão do trabalho muito básica, apelando à destreza manual e, sobretudo, à habituação do corpo, chamando-o à disciplina, no qual o ritmo de trabalho é imposto não pela máquina mas pela tarefa diária a que cada operário está obrigado.

É sabido que o taylorismo se baseia na divisão operativa, dita científica, do trabalho, fazendo com que cada operário execute, idealmente, apenas uma única tarefa, se possível abreviada a um gesto simples. Tão simples que, na perspectiva taylorista, um "gorila treinado" poderia executá-la (Harvey 1999: 109). Proposta por Taylor (1998 [1911]) no início do século XX, a "Organização Científica do Trabalho" visava facilitar a utilização de uma mão-de-obra sem experiência de trabalho industrial, garantindo uma elevada produtividade (v. Friedman 1968). Com ela é possível fazer a formação on-job dos trabalhadores de uma forma acelerada no fim da qual eles estão aptos a realizar as tarefas atribuídas com um nível de desempenho comparável ao dos melhores. O modelo taylorista não é nada sem uma hierarquia - expressão concreta das relações de força no espaço de produção e do poder patronal sobre os operários - que imponha a disciplina e a execução das tarefas. Na fábrica é bem nítida a clássica separação entre realização e direção. Esta é detentora da autoridade e dos saberes gestionários e técnicos, cabendo-Ihe a definição dos objetivos e das estratégias empresariais, bem como a organização e o controle de todas as tarefas no espaço da produção. Como o organograma da fábrica (figura 1) torna evidente, a administração, sediada em Maputo, é detentora do comando "estratégico", nomeadamente ao nível financeiro. Afastada fisicamente do contato regular com o espaço da produção, é ao gerente que delega o poder. $\mathrm{Na}$ dependência direta deste está o chefe da produção. Apesar de hierarquicamente subordinado, o saber técnico que mais ninguém detém na fábrica constitui um capital suficiente para lhe conferir uma autonomia relevante.

Figura 1. Organograma da fábrica

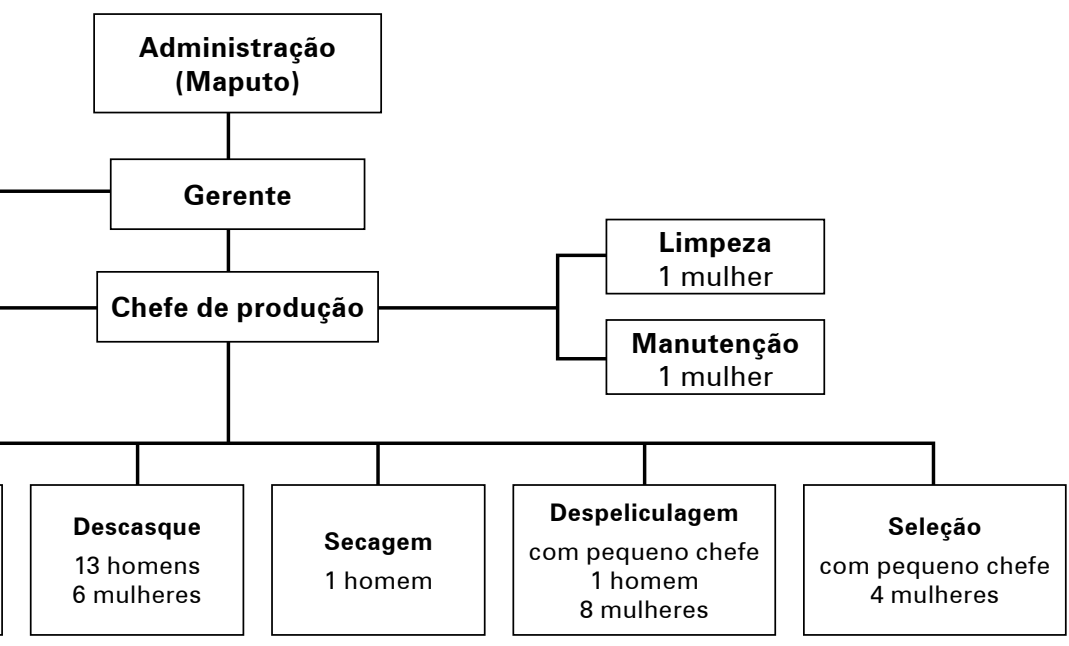


Se em muitos casos é freqüente a divisão entre os que estão em cima, no andar superior ocupado pela direção e administrativos, face aos que estão em baixo, na zona da produção (v. Moulinié 1993), nesta fábrica a separação é ainda mais física. Enquanto que os operários ocupam o edifício principal, o gerente tem o seu pequeno escritório num outro edifício, muito próximo da entrada da fábrica. Esta distinção espacial prolonga-se para além do próprio tempo de trabalho, na medida em que o gerente e o encarregado fazem as suas refeições no edifício de alvenaria que lhes serve também de alojamento, ao passo que os operários almoçam no espaço exterior, à sombra de uma das árvores aí existentes. Ou seja, o poder exprime-se não apenas sob a forma de ordens ou sanções mas também nas práticas cotidianas e nos usos diferenciados do espaço. Aproximando-se dos demais operários pelo fato de não serem detentores dos meios de produção, as chefias afastam-se deles enquanto agentes do poder patronal responsáveis pelo cumprimento dos ritmos de produção e da disciplina estabelecidos. Assim, é pertinente considerar que "a posição dos encarregados é, efectivamente, a mais ambígua no âmbito do sistema de poder da empresa. É o lugar de fronteira que marca a clivagem classista entre o poder operário e o capitalista" (Estanque 2000: 266). Embora possam, na interação face-a-face proteger os seus subordinados, nos momentos graves, como greves e outros conflitos abertos, tomam sempre o partido do patrão. Como justamente assinalou um operário, acerca do chefe de produção, "sabe muito mas não tem para onde ir. As empresas por onde passou estão todas fechadas. Por isso toma sempre o partido do patrão contra os trabalhadores". O grosso da força de trabalho masculina desempenha tarefas nos setores considerados próprios dos homens, como a calibragem, o cozimento, a manutenção e a vigilância. No descasque, um outro setor visto como masculino, têm a companhia de seis colegas do sexo feminino. Às mulheres estão entregues as tarefas consideradas adequadas à sua condição, tais como despeliculagem, seleção, limpeza e serviços domésticos, setores onde não encontramos qualquer homem (v. figura 2).

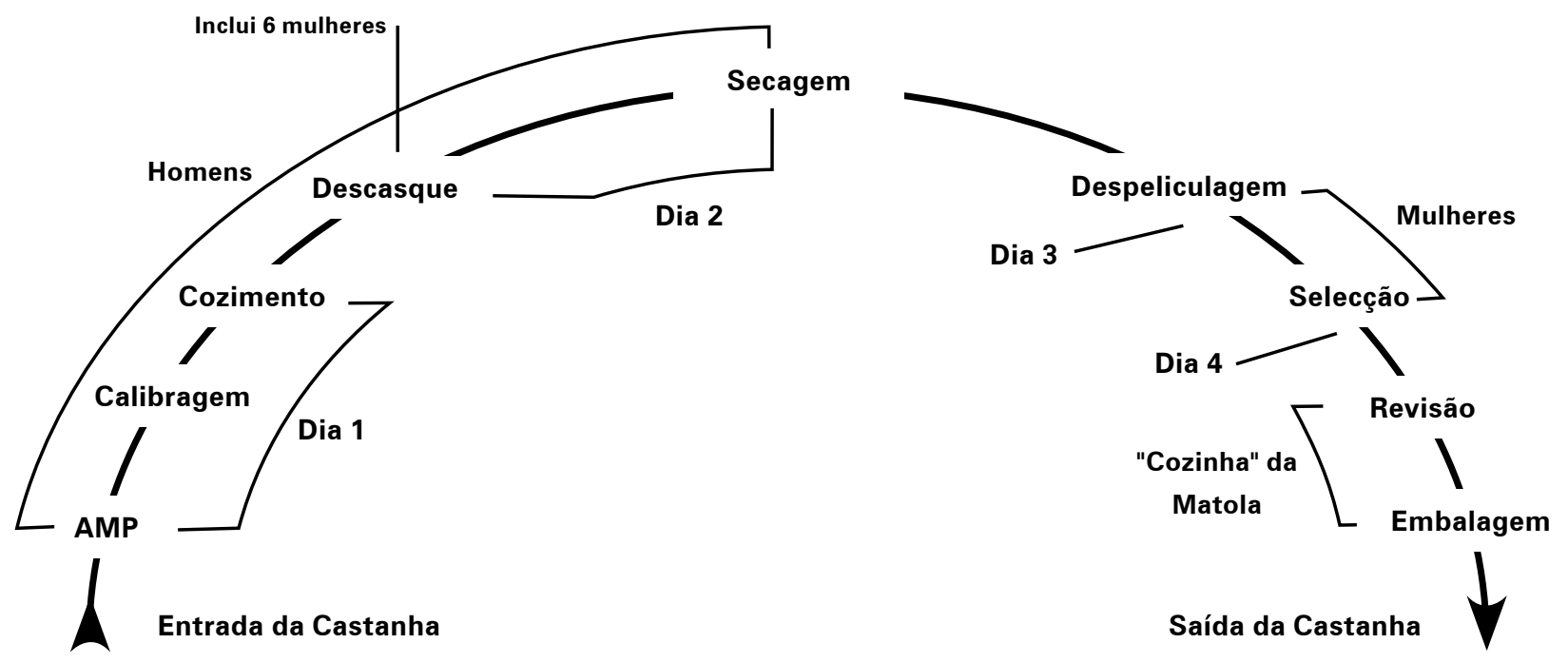

Figura 2. Cadeia operatória da fábrica, com distribuição de funções por sexo e tempos de produção 
No essencial, a fábrica reproduz as diferenças ocupacionais segundo o sexo existentes noutros espaços da vida cotidiana, em especial no doméstico, no qual as mulheres estão vinculadas a trabalhos ligados à produção, manuseio e confecção de alimentos, muitos deles exigindo destreza manual:

“Isso depende da natureza do próprio trabalho. A maneira como se faz o trabalho [de despeliculagem e de seleção] merece mesmo ser para senhoras. É um trabalho com todo o jeito de uma senhora. O que é o trabalho de uma seleção? As senhoras em casa estão a selecionar amendoim para poderem preparar as comidas, lá também estão a selecionar amêndoa da mesma espécie" (Muthemba, operário).

Esta situação tem conseqüências ao nível da mobilidade no espaço da produção. Todas as operárias não podem aspirar a mais do que serem chefes do setor da despeliculagem ou da seleção, posições que não as libertam, sobretudo a primeira, do cumprimento da tarefa em condições idênticas às das suas companheiras. Apesar de não existirem canais institucionalizados de mobilidade no espaço da produção, ser mulher, mesmo quando executa tarefas de alguma exigência, como na seleção, funciona como um fator limitativo para a promoção hierárquica.

A transformação da castanha (a matéria-prima) em amêndoa de caju (o produto final) implica a combinação de operações técnicas precisas ao longo de diversas fases que envolvem matéria-prima, instrumentos de produção e atores sociais, com os seus saberes e gestos inseparáveis dos corpos que os colocam em prática ${ }^{3}$, enquadrados por um dispositivo de organização do trabalho que inclui gestão do tempo, controle e vigilância (v. quadro 1). Estamos perante a cadeia operatória cujo estudo deverá, segundo Martinelli (1991: 66), procurar identificar o modo como os atores sociais organizam as operações técnicas, as dispõem numa dada ordem, sempre influenciados pelos constrangimentos existentes e as opções disponíveis. Como é manifesto nesta fábrica, a análise da cadeia operatória coloca em evidência não apenas os aspectos técnicos e o modelo de organização engendrado, nomeadamente os instrumentos de produção utilizados, os tempos de trabalho e as formas de controle, como salienta também o caráter social da produção, quer dizer, a necessidade de os operários colocarem em prática formas de coordenação do trabalho e de cooperação no espaço de produção. Como se verá de imediato, com a discussão dos efeitos produzidos pela mudança técnica, esta cadeia operatória sujeita os operários a ritmos de trabalho muito intensos e marcados por gestos simples repetidos quase até à exaustão, em troca de um salário que está longe de corresponder às necessidades vitais dos que dele dependem ${ }^{4}$. 
Quadro 1. Cadeia operatória do processamento da castanha de caju

\begin{tabular}{|c|c|c|c|c|c|c|}
\hline $\begin{array}{c}\text { Castanha in } \\
\text { natura }\end{array}$ & $\begin{array}{c}\text { Castanha } \\
\text { calibrada }\end{array}$ & $\begin{array}{c}\text { Castanha } \\
\text { cozida }\end{array}$ & \multicolumn{1}{|c|}{$\begin{array}{c}\text { Amêndoa } \\
\text { sem casca }\end{array}$} & $\begin{array}{c}\text { Amêndoa } \\
\text { estufada }\end{array}$ & $\begin{array}{c}\text { Amêndoa } \\
\text { sem película }\end{array}$ & $\begin{array}{c}\text { Amêndoa } \\
\text { selecionada }\end{array}$ \\
\hline Armazenagem & Calibragem & Cozimento & Descasque & Secagem & Despeliculagem & Seleção \\
\hline
\end{tabular}

\begin{tabular}{|c|c|c|c|c|c|c|c|}
\hline 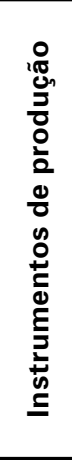 & $\begin{array}{l}\text { Sacos de } \\
\text { serapilheira. } \\
\text { Carrinho de } \\
\text { mão. }\end{array}$ & $\begin{array}{l}\text { Calibrador. } \\
\text { Latas de } \\
\text { alumínio. } \\
\text { Sacos de } \\
\text { serapilheira. }\end{array}$ & $\begin{array}{l}\text { Caldeiras de } \\
\text { vapor e de } \\
\text { cozimento. } \\
\text { Bomba de } \\
\text { água, forno, } \\
\text { manômetro } \\
\text { de } \\
\text { temperatura } \\
\text { da água e } \\
\text { relógio para } \\
\text { controle do } \\
\text { tempo de } \\
\text { cozimento. } \\
\end{array}$ & $\begin{array}{l}\text { Bancada com } \\
\text { máquina de } \\
\text { descasque. } \\
\text { Faca pequena } \\
\text { para separação } \\
\text { completa da } \\
\text { amêndoa da } \\
\text { casca. }\end{array}$ & $\begin{array}{l}\text { Estufa.Forno. } \\
\text { Motor diesel. } \\
\text { Manômetro } \\
\text { de } \\
\text { temperatura } \\
\text { da estufa. }\end{array}$ & $\begin{array}{l}\text { Bacias de } \\
\text { plástico. } \\
\text { Peneiras de } \\
\text { pequena } \\
\text { dimensão para } \\
\text { uso manual. } \\
\text { Faca pequena } \\
\text { para separação } \\
\text { completa da } \\
\text { amêndoa da } \\
\text { película. }\end{array}$ & \begin{tabular}{|l|} 
Bacias de \\
plástico. \\
Cadernos para \\
registro da \\
produção.
\end{tabular} \\
\hline 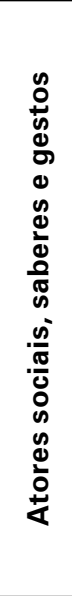 & $\begin{array}{l}\text { Homens. } \\
\text { Trabalho } \\
\text { braçal não } \\
\text { especializa-do. } \\
\text { Enchimento } \\
\text { dos sacos, } \\
\text { empilhamen- } \\
\text { to e transporte } \\
\text { da castanha } \\
\text { para o } \\
\text { calibrador. } \\
\text { Estes } \\
\text { trabalhadores } \\
\text { são também } \\
\text { responsáveis } \\
\text { pela } \\
\text { calibragem. }\end{array}$ & $\begin{array}{l}\text { Homens. } \\
\text { Trabalho } \\
\text { braçal. } \\
\text { Exige um } \\
\text { conhecimen- } \\
\text { to rudimentar } \\
\text { da numeração. } \\
\text { Colocação } \\
\text { da castanha } \\
\text { no calibrador } \\
\text { com o auxílio } \\
\text { de latas de } \\
\text { alumínio. } \\
\text { Movimenta- } \\
\text { ção manual do } \\
\text { calibrador. }\end{array}$ & $\begin{array}{l}\text { Homens. } \\
\text { Trabalho } \\
\text { braçal. } \\
\text { Exige um } \\
\text { conhecimen- } \\
\text { to rudimentar } \\
\text { da } \\
\text { numeração } \\
\text { e do tempo } \\
\text { horário. } \\
\text { Movimento } \\
\text { manual da } \\
\text { bomba de } \\
\text { água. }\end{array}$ & \begin{tabular}{|l|} 
Homens. \\
Nesta fase \\
operatória \\
trabalham \\
também 6 \\
mulheres. \\
Trabalho \\
corporal \\
exigindo \\
uma grande \\
coordenação \\
de \\
movimentos. \\
Aprendiza- \\
gem mais \\
demorada (4 a \\
8 semanas).
\end{tabular} & \begin{tabular}{|l|} 
Homem. \\
Exige \\
algumas \\
competências \\
técnicas \\
no domínio \\
mecânico \\
e um \\
conhecimen- \\
to rudimentar \\
do tempo \\
horário.
\end{tabular} & $\begin{array}{l}\text { Mulheres. } \\
\text { Trabalho } \\
\text { manual simples } \\
\text { e repetitivo. } \\
\text { Aprendiza- } \\
\text { gem muito } \\
\text { rápida, quase } \\
\text { imediata. Não } \\
\text { exige qualquer } \\
\text { competência } \\
\text { escolar ou } \\
\text { técnica. }\end{array}$ & \begin{tabular}{|l} 
Mulheres. \\
Trabalho \\
manual de \\
aprendiza-gem \\
demorada e \\
relativamente \\
complexa. \\
Exige um \\
conhecimen- \\
to preciso de \\
todos os tipos \\
de amêndoa, \\
implicando um \\
treino visual \\
apurado e \\
uma literacia \\
rudimentar.
\end{tabular} \\
\hline 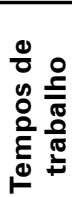 & \multicolumn{4}{|c|}{$\begin{array}{l}\text { Execução da tarefa diária prevista. Normalmente das } 5 \text { às } \\
\text { 14h30min, com interrupções para o “mata-bicho" e o almoço. }\end{array}$} & \multicolumn{3}{|c|}{$\begin{array}{l}\text { Execução da tarefa diária prevista. Normalmente } \\
\text { das } 7 \text { às } 18 \mathrm{~h} \text {, com interrupções para o "mata- } \\
\text { bicho" e o almoço. }\end{array}$} \\
\hline
\end{tabular}




\begin{tabular}{|c|c|c|c|c|c|}
\hline 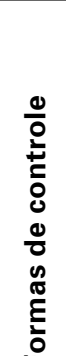 & $\begin{array}{l}\text { Vigilância direta da hierarquia. Controle da } \\
\text { castanha movimentada. }\end{array}$ & $\begin{array}{l}\text { Cumprimento } \\
\text { da tarefa } \\
\text { prevista, } \\
\text { aferida por } \\
\text { pesagem. A } \\
\text { vigilância direta } \\
\text { da hierarquia } \\
\text { tem um papel } \\
\text { secundário. }\end{array}$ & $\begin{array}{l}\text { Cumprimento } \\
\text { da tarefa } \\
\text { prevista, } \\
\text { aferida por } \\
\text { pesagem. } \\
\text { A vigilância } \\
\text { direta da } \\
\text { hierarquia } \\
\text { tem um papel } \\
\text { secundário. }\end{array}$ & $\begin{array}{l}\text { Vigilância direta } \\
\text { da hierarquia. } \\
\text { Controle da } \\
\text { amêndoa } \\
\text { movimentada }\end{array}$ & $\begin{array}{l}\text { Vigilância } \\
\text { direta da } \\
\text { hierarquia. O } \\
\text { controle por } \\
\text { pesagem e } \\
\text { registro das } \\
\text { quantidades } \\
\text { apuradas é } \\
\text { fundamental. }\end{array}$ \\
\hline
\end{tabular}

\section{MUDANÇA TÉCNICA E RECOMPOSIÇÃO DA INDÚSTRIA DO CAJU}

Na indústria do caju em Moçambique é muito forte a marca da mudança técnica. Desde que as primeiras fábricas bem sucedidas começaram a funcionar, na década de 50, o processamento de castanha de caju sofreu alterações técnicas profundas. Elas são particularmente notórias nos últimos anos, com o retorno, como é o caso da fábrica aqui analisada, aos sistemas produtivos apoiados em mão-de-obra intensiva e técnicas simples. Circunscrevendo a discussão ao último período de mudança técnica, iniciado em meados dos anos 90, o confronto opõe os sistemas produtivos baseados na utilização intensiva de capital e técnicas complexas aos sistemas produtivos baseados na utilização de artefatos mecânicos simples e mão-de-obra intensiva. A opção pelos sistemas simples tem conseqüências ao nível do enraizamento e expansão da cultura técnica complexa. A introdução em Moçambique de mecanismos mecânicos sofisticados nas fábricas de caju exigiu a formação de metalúrgicos, serralheiros e outros operários especializados que acabaram por produzir e disseminar uma nova cultura de trabalho, um saberfazer hoje velho de décadas partilhado por milhares de trabalhadores que aprenderam, dominam e, sobretudo, acreditam na superioridade da mecanização. Espaços de saber técnico, estas fábricas funcionaram como alavanca para o crescimento e consolidação de setores correlativos essenciais para o incremento da produtividade, sem o qual os salários dificilmente sairão do patamar em que se encontram, manifestamente insuficiente para assegurar a reprodução social dos operários.

Ainda que os protagonistas deste confronto em Moçambique - industriais, consultores, técnicos e outros especialistas - se tenham ocupado sobretudo com a análise comparativa da eficiência técnica obtida por estes diferentes sistemas, a escolha entre um ou outro vai muito além deste aspecto, não se reduzindo, digamos assim, ao aspecto estritamente técnico. Como justamente refere Geslin (1999: 7-9), na esteira do argumento desenvolvido por Martinelli (1987), a escolha técnica tem uma dimensão social à qual não pode escapar e que importa examinar para melhor a compreender. Apoiando-se nas contribuições decisivas produzidas pelos teóricos da Escola de Frankfurt (v., entre outros, Habermas 1994), Leite (2005: 46) salienta precisamente que os interesses e os objetivos sociais, em especial os dos grupos dominantes, estão já inseridos no próprio desenho dos sistemas técnicos, pelo que 
neles se projetam o que uma dada sociedade num contexto histórico concreto pretende fazer com os indivíduos e os objetos materiais. Neste sentido, Harvey (1999: 100) mostra-nos que as técnicas e as tecnologias são a forma material do processo de trabalho através da qual as forças produtivas e as relações de produção se exprimem. Longe de serem socialmente neutras, sublinha Martinelli (1987: 321-322), ambas têm um enorme impacto na organização do trabalho e estão indissoluvelmente ligadas às lutas sociais e às relações de força que opõem os trabalhadores ao capital e aos conflitos que ocorrem nos espaços de produção (Burawoy 1979: 47). Quer dizer, as escolhas técnicas não podem ser desconectadas das mudanças sociais e das estruturas no interior das quais elas fazem sentir os seus efeitos nem, tampouco, a sua crítica pode ser separada da crítica das formas organizacionais engendradas nos espaços de produção. Mais, elas são inseparáveis das políticas de produção, designadamente do modo como se regula o trabalho no espaço de produção e do papel nele desempenhado pelos operários. Como os capitalistas não operam no vazio, antes se confrontam cotidianamente com diversos constrangimentos, tais como a luta de classes, os limites do conhecimento técnico-científico, os custos com a substituição dos equipamentos ou da sua simples operação e manutenção, as escolhas técnicas constituem um recurso precioso para o capital na sua procura permanente das melhores condições para a realização de mais-valias (Harvey 1999: 117-124). Porém, evitando-se um erro muito comum, as escolhas técnicas não implicam, de forma mecânica, a intensificação e a complexificação dos processos produtivos. De fato, não se pode esquecer que o que interessa ao capital é "o caráter mercadoria do produto" (Palloix 1974: 208), isto é, não interessa o modo como se produz mas antes o que se produz. Não sendo o modo como se produz um fim em si mesmo mas simplesmente um meio para a reprodução alargada do capital, no caso da indústria do caju o que realmente conta é a amêndoa de caju e não as técnicas e os processos utilizados para chegar até ela. Quer dizer, os sistemas produtivos complexos, nas condições em que o processamento do caju em Moçambique se realiza atualmente, não trazem qualquer vantagem para os detentores do capital. Face à desregulação das relações de trabalho, à abundância de mãode-obra e à lentidão da recuperação do capital investido em equipamentos, a forma mais rápida para a obtenção de mais-valias assenta, como bem o compreendeu a burguesia moçambicana emergente, na utilização intensiva da força de trabalho - o capital variável da esfera produtiva que mais próximo se encontra do capital-dinheiro, precisamente aquele que, na fórmula geral de Marx (1974 [1867]), significa "liquidez, flexibilidade e liberdade de escolha" (Arrighi 1996: 5). Tal como acontecia no século XIX com as mulheres inglesas que puxavam os barcos nos canais, em determinadas circunstâncias o investimento de capital em artefatos e outros meios de produção pode não se justificar face ao custo diminuto dos salários pagos aos trabalhadores.

A utilização intensiva da força de trabalho baseada, no caso do processamento do caju, no trabalho à tarefa (v. quadro 1) é inseparável do ordenamento jurídico e legislativo atualmente em vigor. É ele que permitiu tornar legal e, de certa forma, "naturalizar" a sobre-flexibilização, adotando designadamente um regulamento ordenador do trabalho rural que possibilitou a remoção de todos os estorvos legais ao trabalho à tarefa, flexível e conforme as necessidades da indústria, esmagando-se assim os custos salariais, dos quais depende a viabilidade dos sistemas produtivos simples. Trata-se de levar o salariato ao seu limite extremo, o da máxima flexibilidade que admite a todo o tempo a dispensa do trabalhador. Mas não só: como argumenta Meillassoux (1997: 13ss), este regime salarial, dominante nos países periféricos, configura uma situação de sobre-exploração do trabalho, isto é, 
de captação da substance vivante do trabalhador por via da diminuição da saúde devido a doenças profissionais, violação da integridade física sob a forma de acidentes de trabalho e redução da esperança de vida, enfim, formas de extração do lucro através da mutilação da vida do operário que escapam ao cálculo salarial da empresa.

\section{CONCLUSÃO}

Ao longo dos diversos períodos pelos quais passou o setor industrial e, mais amplamente, a economia do caju em Moçambique, o poder estatal jogou sempre um papel importante na definição do caminho trilhado, sobretudo nas suas viragens reconfigurativas. Nesses momentos, marcados pela instabilidade política e lutas sociais encarniçadas, o fator jurídico assumiu uma função fundamental, legitimando a nova ordem político-social e os seus interesses dominantes. A ação do Estado é condicionada pelas lutas entre as diversas forças sociais que tentam impor a configuração que lhes parece melhor servir a defesa e o alargamento dos seus benefícios e privilégios. Quer dizer, em cada momento as escolhas tomadas resultaram da correlação de forças existente. Mesmo aquelas que os consultores neoliberais pretendem que sejam entendidas como de natureza estritamente técnica - fábricas de grande dimensão e sistemas produtivos complexos versus fábricas de pequena dimensão e sistemas produtivos simples - estão atravessadas por relações de força e poder eminentemente políticas.

Como foi discutido, a escolha técnica é inseparável das lutas sociais, nomeadamente daquelas que ocorrem no interior dos espaços de produção. Em concreto, o triunfo das pequenas fábricas é conseqüência direta das novas condições econômicas que favorecem o esmagamento dos salários e o aumento desmesurado da disponibilidade de força de trabalho em Moçambique, tornando supérfluo, não econômico segundo a racionalidade liberal, o investimento em capital fixo. Explorando uma alteração profunda na correlação de forças entre o capital e o trabalho, provocada por um incremento muito substancial da quantidade de força de trabalho disponível, pelo crescimento da produção facilitado pelo desenvolvimento das tecno-ciências em diversos outros países periféricos concorrentes, como o Brasil e a Índia e, em menor importância, por uma oferta crescente dos produtos de substituição criados pelas indústrias alimentares, o capital na indústria de caju em Moçambique trocou, como mecanismo fundamental da acumulação e eventualmente de modo transitório, a inovação técnica pela compressão dos custos salariais e a redução dos investimentos em máquinas e equipamentos de produção.

Estas mudanças têm conseqüências bem concretas para os operários, como os da pequena fábrica de Jongué. O sistema técnico confronta-os com um incremento muito notório da rudeza do trabalho, marcada pela violência dos ritmos de produção e o desgaste físico severo, incluindo lesões profissionais e deformações corporais. Por outro lado, as condições políticas e sociais atualmente prevalecentes permitiram uma compressão brutal dos salários, ao ponto de eles serem insuficientes para assegurar a reprodução social dos operários. Apesar disto, o assalariamento é decisivo para o acesso regular, se bem que marginal, dos operários e das suas famílias às trocas de mercado, atenuando a dependência extrema em relação à terra e aos ganhos, sempre incertos, proporcionados pela venda dos pequenos excedentes da produção agrícola. Viver fora dos circuitos monetários e das trocas de mercado implica um cotidiano ferido por privações extremas e uma 
fruição muito limitada de determinados bens e serviços aos quais só é possível aceder através do poder de compra caucionado pela moeda.

Fernando Bessa Ribeiro é antropólogo, professor do Departamento de Economia e Sociologia da Universidade de Trás-os-Montes e Alto Douro, pesquisador efetivo do Centro de Estudos Transdisciplinares para o Desenvolvimento e pesquisador associado do Núcleo de Estudos em Sociologia da Universidade do Minho. 


\section{NOTAS}

1 A pesquisa sobre empresas e trabalho nas fábricas é um terreno pouco freqüentado pela antropologia produzida em Portugal e pelos portugueses que fazem antropologia fora de portas. Apesar de pouco numerosos, os estudos já publicados, mormente pelos autores acima citados, oferecem-nos perspectivas estimulantes sobre esta temática, fato que tem contribuído para a consolidação desta linha de investigação em Portugal.

2 A Caju de Moçambique era a empresa estatal que controlava, no período revolucionário, a maior parte das fábricas de processamento de caju mecanizadas construídas pelo capital privado colonial. A privatização do aparelho produtivo nos anos 90 conduziu ao seu desmantelamento.

3 Sobre o corpo e as técnicas v. Durand (2002: 275ss).

4 Para a visualização das diversas fases da cadeia operatória v. o filme Salvador (Ribeiro 2003). 


\section{REFERÊNCIAS BIBLIOGRÁFICAS}

ARRIGHI, Giovanni. 1996. O Longo Século XX: dinheiro, poder e as origens do nosso tempo. São Paulo: UNESP.

BAZIN, Laurent. 2001. “Industrialisation, Désindustrialisation”. In Laurent Bazin e Monique Selim (avec la contribution de Gérard Althabe) Motifs Economiques en Anthropologie. Paris: L'Harmattan.

BURAWOY, Michael. 1979. Manufacturing Consent: changes in the labour process under monopoly capitalism. Chicago: The University of Chicago Press.

BURAWOY, Michael et al. 2000. Global Ethnography: forces, connections and imaginations in a postmodern world. Berkeley: The University of California Press.

DURAND, Jean-Yves. 2002. Le Sens des Profondeurs. Ethnographie d'une pratique divinatoire: la sourcellerie, entre hydrogéologie et parasciences. Tese de doutoramento. Aix-en-Provence: Universidade de Provença.

DURÃO, Susana. 2003. Oficinas e Tipógrafos: cultura e quotidianos de trabalho. Lisboa: Dom Quixote.

ESTANQUE, Elísio. 2000. Entre a Fábrica e a Comunidade: subjectividades e práticas de classe no operariado do calçado. Porto : Afrontamento.

FLAMANT, Nicolas e Monique Jeudy-Ballini. 2002. "Le Charme Discret des Enterprises: I'ethnologie en milieu industriel". Terrain 39: 5-16.

FRIEDMAN, Georges. 1968. O Futuro do Trabalho Humano. Lisboa: Moraes.

GEERTZ, Clifford. 1992. La Interpretación de las Culturas. Barcelona: Gedisa.

GESLIN, Philippe. 1999. L'Apprentissage des Mondes: une anthropologie appliquée aux transferts de technologie. Paris : Éditions Octarès et Fondation de la Maison des Sciences de l'Homme.

GRANJO, Paulo. 2003. "A Mina Desceu à Cidade: memória histórica e a mais recente indústria moçambicana". Etnográfica II(2): 403-428.

2004. "Trabalhamos Sobre um Barril de Pólvora": homens e perigo na refinaria de Sines. Lisboa: Instituto de Ciências Sociais.

HABERMAS, Jürgen. 1994. Técnica e Ciência como Ideologia. Lisboa: Edições 70.

HARVEY, David. 1999. The Limits to Capital. Londres: Verso.

LAZARUS, Sylvain. 2001. "Anthropologie Ouvrière et Enquêtes d'Usine: état des lieux et problematique". Ethnologie Française XXXI(3): 389-400.

LEITE, Ivonaldo. 2005. "A Relação Novas Tecnologias, Mercado de Trabalho e Educação como Tema e como Problema". In Alder J. F. Calado e Alexandre Tavares da Silva (orgs.) Cidadania no Horizonte do Trabalho: reflexóes sócio-históricas e pedagógicas. João Pessoa: Idéia/Edições FAFICA.

MARTINELLI, Bruno. 1987. “La Fin et les Moyens: I'ethnologie et l'intervention technologique”. L'Uomo XI(2): 319-341.

. 1991. “Une Chaîne Opératoire Halieutique au Togo”. In Hélène Balfet (ed.) Observer l'Action Technique: des chaines opératoires, porquoi faire. Paris: Éditions du CNRS. 
MARX, Karl. 1974 [1867]. O Capital, vol. I. Lisboa: Delfos.

MEILLASSOUX, Claude. 1997. L'Économie de la Vie. Lausanne: Page2.

MOULINIÉ, Véronique. 1993. “Une Ethnographie du Pouvoir en Usine”. Terrain 21: 129-142.

PALLOIX, Christian. 1974. As Firmas Multinacionais e o Processo de Internacionalização. Lisboa: Estampa.

PORTELA, José. 1985. “Observação Participante (Reflexões sobre uma Experiência)". Cadernos de Ciências Sociais 3:157-176.

RIBEIRO, Fernando Bessa. 2003. Salvador. Vila Real, UTAD - SDE - Audiovisuais (documentário, 43 minutos).

2004. Sistema Mundial, Manjacaze e Fábricas de Caju: uma etnografia das dinâmicas do capitalismo em Moçambique. Tese de doutoramento. Vila Real: Universidade de Trás-os-Montes e Alto Douro.

SELIM, Monique. 2001. "Entreprise et Mondialisation". In Laurent Bazin e Monique Selim (avec la contribution de Gérard Althabe) Motifs Economiques en Anthropologie. Paris: L'Harmattan.

TAYLOR, Frederick Winslow. 1998 [1911]. The Principles of Scientific Management. Nova lorque: Dove Publications.

WOLF, Eric R. 1982. Europe and the People Without History. Berkeley: University of California Press.

WOLF, Eric R. with Sydel Silverman. 2001. Pathways of Power: building an anthropology of the modern world. Berkeley: University of California Press. 


\section{Trabalho e Políticas de Produção numa Fábrica de Caju em Moçambique}

\section{RESUMO}

No quadro da reflexão compreensiva sobre as políticas de produção e da mudança técnica na indústria do caju em Moçambique procura-se identificar e examinar as origens da empresa, a organização do trabalho e o processo produtivo numa fábrica de processamento de castanha de caju neste país do sul do continente africano. $\mathrm{O}$ artigo começa por refletir sobre o trabalho de campo etnográfico nos espaços de produção, nomeadamente no que concerne ao papel a ser desempenhado pelo antropólogo. Esclarecida a prática empreendida pelo autor, passase à descrição do processo de instalação da fábrica e à análise da organização do trabalho e da produção, com uma atenção especial ao modo como os operários nela se inscrevem. Por último reflete-se sobre a mudança técnica neste setor industrial, mostrando-se o seu caráter profundamente histórico, quer dizer, o papel decisivo desempenhado nas escolhas técnicas pelas estruturas políticas e econômicas, algumas de dimensão global, e pelas lutas sociais que opõem o capital ao trabalho.

PALAVRAS-CHAVE: trabalho de campo, Moçambique, fábrica de caju, políticas de produção, mudança técnica.

\section{Work and Production Policies in a Cashew Factory in Mozambique}

\section{ABSTRACT}

In the scope of a comprehensive reflection on the production policies and technical changes in cashew industry in Mozambique, this article attempts to identify and examine the company's original background, as well as its work organization and the productive process in a cashew nut processing factory in Southern Africa. It starts by reflecting on the ethnographic fieldwork in the production spaces, namely concerning the role played by the anthropologist. Having exposed his practical approach, the author goes on to describe the factory's installment process and analyzes the work and production organization, focusing particularly on the role played by the workers. At last, there's a reflection on the technical changes in this industrial sector, revealing its deeply historical character, meaning, the fundamental role played by the economical and political structures within the technical schools, some of a global scope, and by the social struggles that oppose work to capital.

KEYWORDS: fieldwork, Mozambique, cashew factory, production policies, technical changes. 
182 